\title{
Uma reflexão sobre o ensino de Astronomia na perspectiva da Base Nacional Comum Curricular
}

\author{
A reflection on the teaching of Astronomy in perspective of \\ the Common National Base Curriculum \\ J.G.S.L. Junior ${ }^{1 *}$; J.E. Andrade ${ }^{2}$; J.M. Dantas ${ }^{3}$; L.M. Gomes ${ }^{4}$ \\ ${ }^{1}$ Faculdade de Física/Instituto de Ciências Exatas/Programa Nacional de Mestrado Profisional em Ensino de Física, \\ Universidade Federal do Sul e Sudeste do Pará, 68507-590, Marabá - Pará, Brasil \\ ${ }^{2}$ Faculdade de Engenharia Mecânica/Instituto de Geociências e Engenharias, Universidade Federal do Sul e Sudeste \\ do Pará, 68507-590, Marabá - Pará, Brasil \\ ${ }^{3}$ Faculdade de Computação e Engenharia Elétrica/Instituto de Geociências e Engenharias, Universidade Federal do \\ Sul e Sudeste do Pará, 68507-590, Marabá - Pará, Brasil \\ ${ }^{4}$ Faculdade de Física/Instituto de Ciências Exatas, Universidade Federal do Sul e Sudeste do Pará, 68507-590, \\ Marabá - Pará, Brasil \\ *gidauto@unifesspa.edu.br
}

(Recebido em 29 de agosto de 2016; aceito em 14 de outubro de 2016)

\begin{abstract}
Tema recorrente da política educacional brasileira, durante muitos anos discutiu-se a possibilidade da implementação de um Currículo Nacional que contemplasse de forma igualitária o acesso ao ensino e aprendizado de modo a garantir as especificidades regionais, culturais e sociais do país. Hoje, essa expectativa tornou-se realidade. A proposta da Base Nacional Comum Curricular (BNCC) é de justamente fomentar e subsidiar um currículo comum que atenda a todas as expectativas da comunidade escolar e mais, com a participação efetiva em todo o processo dos diversos grupos e segmentos da sociedade civil brasileira nas discussões. Evidentemente, que a BNCC não resolverá todos os problemas, entretanto, acredita-se para a maioria dos especialistas que amenizará boa parte deles. Como a BNCC traz uma discussão ampla a respeito, esse artigo, limitou-se a discussão na Unidade Curricular do ensino de Astronomia na perspectiva dos eixos formativos da BNCC, apresentando as potencialidades e fragilidades de sua inserção na dinâmica da escola, com foco nos processos formativos de docência, nos livros didáticos e no regime de período letivo atual, além é claro, da complexidade dos conteúdos de Física, especificamente, os conteúdos de Astronomia, suas interpretações, os processos metodológicos envolvidos no ensino e perspectivas futuras. Atualmente, o processo de discussão a respeito da BNCC continua, porém, a análise e a visão geral de como a BNCC atuará nos fornece um delineamento inicial sobre as possíveis estratégias ou técnicas de ensino nessa perspectiva tão recente de um currículo comum.
\end{abstract}

Palavras-chave: Currículo Comum, Ensino de Astronomia, Livro Didático.

Recurring theme of Brazilian educational policies, for many years discussed the possibility of implementing a National Curriculum that considered equally access to education and learning in order to ensure the specific regional, cultural and social of the country. Today, this expectation has become reality. The proposal Curriculum Common National Base (BNCC) is precisely to encourage and support a common curriculum that meets all expectations of the school community and more, with the effective participation in the whole process of the various groups and segments of Brazilian civil society in discussions. Evidently, that BNCC not solve all the problems, however, it is believed to most experts that will ease many of them. As the BNCC brings a broad discussion, this article was limited to the discussion in the Course of Astronomy teaching from the perspective of training axes of BNCC, presenting the strengths and weaknesses of their insertion in the school dynamics, focusing on processes training of teaching, in didactic book and in the current school year regime, and of course, the complexity of the Physics content, specifically, Astronomy content, their interpretations, methodological processes involved in teaching and future prospects. Currently, the process of discussion of the BNCC continues, nevertheless, the analysis and overview of how to act in BNCC provides an initial outline of the possible strategies and teaching techniques in this so new perspective of a common curriculum.

Keywords: Common Curriculum, Astronomy Teaching, Didactic Book. 


\section{INTRODUÇÃO}

De iniciativa do Governo Federal, a proposta para a implementação da Base Nacional Comum Curricular (BNCC) é uma das estratégias estabelecidas pelo Plano Nacional de Educação (PNE) com intuito de melhorar a educação básica, que compreende a educação infantil, o ensino fundamental e o ensino médio. Proposto pelo Ministério de Educação desde o segundo semestre de 2015, a discussão a respeito da proposta para a BNCC tomou proporções gigantescas, por intermédio de grupos da sociedade civil - quer por rodas de conversas disseminadas por encontros presenciais quer por meio de sistema virtual, enfim, independentemente do meio de difusão, a proposta inédita de um currículo que atenda as perspectivas, anseios, desafios de toda a comunidade escolar, nunca antes havia compreendido a participação efetiva e democrática da sociedade desde sua concepção até sua implementação.

Entretanto, há uma preocupação por parte de alunos, professores, entidades da sociedade civil quanto a implementação de um currículo que não diferencie grupos, regiões, classes sociais e pessoas. Diferentes concepções sobre o currículo poderão surgir nesse interim de formulação da BNCC, o que poderá comprometer diferentes visões acerca dos eixos temáticos, porque não dizer a respeito das disciplinas constantes no grupo de ciências da natureza.

A respeito, Arroyo (2011) afirma que o currículo é um território em disputa, justamente por se constituir o núcleo central estruturante da função social da escola. Destarte, o currículo é resultado das relações de poder e interesses nesse campo, evidentemente, que a produção curricular é um fenômeno desigualmente distribuído entre sujeitos e grupos sociais.

Desta forma, o currículo comum não poderá ser somente um documento onde estarão expostos as concepções educativas, objetivos, metodologias e procedimentos de avaliação, porém, sobretudo, um instrumento catalisador, capaz de nortear de maneira eficaz conceitos e elementos que outrora nunca foram apresentados em aulas de física do ensino médio. Acredita-se que a com a BNCC implementada o ensino de um modo geral no país passará por uma série de inovações e que última análise produzirá seus efeitos esperados.

Atualmente, são inúmeras as pesquisas no âmbito do ensino de Física e, no entanto, ainda existem dificuldades significativas quanto à transposição didática dos conceitos, a subutilização dos espaços laboratoriais, a ausência de uma metodologia atrativa de ensino, dentre outras. Com essa nova discussão a respeito da BNCC, há pelo menos uma perspectiva de mudança desse cenário. Há muitos anos as escolas públicas nacionais utilizam os livros didáticos como ferramentas de apoio ao ensino, e até hoje, os livros didáticos de Física trazem os mesmos problemas: ausência de aporte histórico aos conceitos, mitos científicos, elementos de uma pseudo-história, ausência de conteúdos atuais que promovam a curiosidade científica e o protagonismo dentre outros.

A propósito, os PCN preconizam para o ensino médio - Ciências da Natureza na área de Física, o aprendizado do tema estruturador Universo, Terra e Vida, que é composto das unidades temáticas: Terra e Sistema Solar, O Universo e sua Origem e a Compreensão Humana do Universo. Evidentemente, pela ausência de uma carga horária efetiva, torna-se impossível ao professor implementar todos esses temas com apenas duas aulas semanais como de fato acontece em todo o país, aliás, uma das propostas da BNCC é o aumento de carga horária em algumas disciplinas e escolas em tempo integral.

Apesar dos temas estruturantes serem extensos para a implementação conforme estabelecem os PCN, uma proposta de conteúdos mínimos a serem abordados seria mais trivial para a atual carga horária disponível na maioria das escolas públicas do país, as discussões seguem nesse aspecto.

Este artigo propõe a levantar discussões e reflexões sobre essa proposta da BNCC no âmbito do ensino de Física, especificamente, quanto ao ensino da Astronomia e suas vertentes, afinal de contas, esse campo é pouco explorado no ensino médio - apesar dos esforços da Sociedade Astronômica Brasileira (SAB) em parceria com a Agência Espacial Brasileira (AEB) através da realização anual da Olimpíada Brasileira de Astronomia e Astronáutica (OBA) em difundir a Astronomia, alguns livros trazem apenas breves notações sobre o tema e no demais em sua maioria abordam as leis de Kepler e alguns fenômenos relacionados ao Universo, poucos contemplam temas atuais ou temas constantes sequer nos Parâmetros Curriculares Nacionais (PCN). 


\section{FUNDAMENTAÇÃO TEÓRICA}

Considerada por muitos como a mais antiga das ciências, a Astronomia tem fascinado o homem desde os tempos antigos. O fascínio em conhecer o cosmos foi e é objeto de desejo de geração após geração nutrida por vínculos comuns: hora por especulações sobre a origem do Universo (cosmogonia) e hora por interpretações acerca da estrutura do Universo (cosmologia).

Indiscutivelmente, esse tema é fascinante, então porque não explorá-lo nas aulas de ciências ou de Física, nota-se que ao discorre-se sobre esse tema, percebe-se o quanto toda a sala de aula "viaja na imaginação", as dúvidas surgem, os questionamentos e outras indagações. Obviamente, não se tem resposta a todas as indagações levantadas em sala de aula, entretanto, algumas concepções sobre os astros, distâncias, interações com outros temas interdisciplinares podem ser abordados, enfim, o campo de atuação na perspectiva didático-metodológica é imenso quando se trata de um tema dessa magnitude, entretanto, alguns cuidados devem ser tomados em relação à presença de mitos científicos, erros ou factoides históricos.

Antes de discorrer sobre o tema na perspectiva da BNCC, é necessária a retomada de alguns elementos e fatos que antecederam a proposição atual, a retórica da saga dos $\mathrm{PCN}$ e um panorama geral sobre os livros didáticos no que concernem as potencialidades e fragilidades apresentadas.

\subsection{OS PCN E OS LIVROS DIDÁTICOS}

Conforme estabelece o Ministério da Educação (MEC), os PCN para o ensino médio, constituem um programa governamental de reforma curricular aprovado pelo Conselho Nacional de Educação e de acordo com os princípios definidos pela Lei de Diretrizes e Bases da Educação Nacional (LDB - Lei 9394/96). Assim, a LDB fundamenta os PCN no que se refere às intenções legais e pressupostos pedagógicos elaborados para este nível de ensino.

$\mathrm{Na}$ área de Ciências da Natureza, Matemática e suas Tecnologias (Parte III do PCN), especificamente na seção Conhecimentos de Física, acentua-se a importância da Física na formação do cidadão enfatizando o processo histórico. A nova abordagem prevê a estruturação dos conteúdos - feita até então de forma linear - através de eixos temáticos que possibilitam uma maior flexibilidade tanto na escolha de conteúdos quanto na abordagem metodológica, possibilitando ao educando desenvolver uma visão global do mundo e de suas tecnologias. Nesse aspecto os PCN são enfáticos:

\footnotetext{
"Espera-se que o ensino de Física, na escola média, contribua para a formação de uma cultura científica efetiva, que permita ao indivíduo a interpretação dos fatos, fenômenos e processos naturais, situando e dimensionando a interação do ser humano com a natureza como parte da própria natureza em transformação. Portanto, é essencial que o conhecimento físico seja explicado como um processo histórico, objeto de contínua transformação e associado às outras formas de expressão e produção humanas.” (BRASIL, parte III, 2000, p. 24).
}

A utilização dos eixos temáticos possibilita o trabalho com as quatro áreas que compõe a disciplina de ciências: Geociências, Biologia, Química e Física - além de trazer para discussão aspectos sociais da produção científica e suas implicações. "Com isso não se propõe forçar a integração aparente de conteúdos, mas trabalhar conhecimentos de várias naturezas que se manifestam inter-relacionadas de forma real", conforme preconizam os PCN.

Apesar de enfático, os PCN poucos contribuíram para a dialógica entre o eixo temático e a implementação em sala, atualmente, precariamente, as escolas públicas dispõem de um laboratório de informática, imagine um laboratório de multiciências com um aparato voltado a observação espacial, nos padrões atuais seria no mínimo surreal.

Com relação aos livros didáticos, no primeiro aspecto, estes constituem um dos principais recursos utilizados pelos educadores em seu trabalho. "Por longos anos, pesquisadores, apontaram esse recurso como sendo um dos principais responsáveis pela caracterização do ensino de Ciências como conceitualista, teórico e desvinculado da realidade", afirma Guerra (2009).

No segundo aspecto, o livro didático é tratado como um suporte do conteúdo educativo, cuja aquisição venha contribuir com valores transmitidos entre as futuras gerações. $\mathrm{O}$ terceiro aspecto, 
o livro didático transpõe o universo escolar e adentra ao universo ideológico e cultural como instrumento cultivador de valores da sociedade. Por fim o livro didático tem seu status de instrumento pedagógico e auxiliar no processo de ensino aprendizagem.

Dada toda a sua importância, pesquisas mostram que alguns livros didáticos nacionais apresentam vários equívocos científicos com relação a conceitos principalmente históricos, bem como com a ausência de conteúdos importantes a compressão de alguns fenômenos físicos, dentre estes, os fenômenos que envolvem os astros celestes.

Mas de fato, qual o papel do livro didático no ensino? Segundo Bizzo (1998), o livro não deveria se limitar simplesmente ao incentivo à memorização de enunciado, fórmulas ou termos técnicos. Outro ponto importante que destaca ainda é o fato de que as figuras e ilustrações devem cuidar de transmitir a veracidade das informações, por isso, pesquisadores questionam a utilização exclusiva do livro didático como fonte de pesquisa.

\subsection{PRINCÍPIOS NORTEADORES DA BNCC}

Um dos princípios que norteia a BNCC é a conformidade com o Plano Nacional de Educação (PNE), e estabelece que cabe a BNCC definir direitos e objetivos de aprendizagem e desenvolvimento que orientarão a elaboração dos currículos nacionais. $\mathrm{Na}$ BNCC, as concepções de direito de aprendizagem e desenvolvimento são, portanto, balizadoras da proposição dos objetivos de aprendizagem para cada componente curricular.

Do ponto de vista da jurisprudência, ao aluno é garantido o direito ao ensino e ao aprendizado, a proposta da BNCC não é estabelecer um padrão de currículo, ou engessar as instituições mais sim promover o acesso de forma equacional a todos ao ensino e ao aprendizado e consequentemente promover a lei. Ademais, a proposta é fornecer à apropriação de conhecimentos historicamente constituídos que lhes permitam realizar leitura crítica do mundo natural e social, por meio da investigação, reflexão, interpretação, elaboração de hipóteses e argumentação, com base em evidências, colaborando para a construção de uma sociedade solidária, na qual a liberdade, a autonomia e a responsabilidade sejam exercidas.

No subitem a seguir serão delineados os eixos formativos da área, bem como apresentadas as peculiaridades conforme a proposta recente.

\subsection{A ÁREA DE CIÊNCIAS DA NATUREZA NO ENSINO MÉDIO}

A área de Ciências da Natureza corresponde à divisão da área em três componentes curriculares - Biologia, Física e Química, uma organização que responde as razões conceituais e históricas, que reflete o tipo dos conhecimentos tratados e a forma como eles são e foram produzidos, praticamente todas as áreas de conhecimento de Astronomia estão inseridas na área de Física. Estes componentes curriculares devem possibilitar a construção de uma base de conhecimentos contextualizada, envolvendo discussões de temas transversais, nesse aspecto, se faz necessário à integração entre conhecimentos abordados nos vários componentes curriculares da área.

$\mathrm{Na}$ BNCC os eixos formativos que estruturam a aprendizagem a ser conduzida são dimensões do conhecimento físico e orientam o currículo. Na nova proposta são eles: eixos do conhecimento conceitual (CC), eixos da contextualização social, cultural e histórica (CSCH), eixos dos processos e práticas de investigação (PPI), e por último o eixo da linguagem da ciência (LC) que estruturarão a formação pretendida.

Em primeira análise, observa-se que do ponto de vista instrumental, ou seja, tomando os eixos como instrumentos de aferição, os eixos do conhecimento conceitual (CC) são extremamente significantes no processo de ensino aprendizagem em virtude na linearidade das informações com que o estudante adentra no assunto, ou seja, conhecendo o conceito mesmo que de maneira superficial substancia o aprendizado efetivo em uma determinada área do conhecimento científico de forma ordenada e linear.

Os fatores sociocultural e histórico foram levados em consideração nessa proposta, afinal, é impossível produzir conhecimento sem o aporte histórico, social ou cultural. Os processos e práticas pedagógicas de intervenç (PPI), em se tratando dos conteúdos sobre Astronomia, serão imprescindíveis à compreensão de conceitos dotados de abstracionismo, e, por fim, o eixo da 
linguagem da ciência (LC) - como conhecer algo sem se ter pelo menos o domínio da linguagem? muitas vezes, o estudante não consegue entender a linguagem da disciplina que estuda, no caso, da Física, termos como referencial, inércia, no caso da Astronomia, afélio, ano-luz, nebulosas e outros, são alguns termos incompreensíveis principalmente para alunos advindos do nível fundamental que nunca tiveram contanto com essa linguagem extremamente científica.

Para os autores da BNCC os eixos evidenciam diferenças e especificidades que merecem ser preservadas nessa etapa de escolarização, permitindo que as diversas Ciências da Natureza lancem seus múltiplos e complementares olhares para os fenômenos e propiciem aos estudantes da Educação Básica um diálogo inteligente com o mundo à nossa volta.

Posteriormente, nesse artigo, será apresentado um exemplo aplicado a um dos quatros eixos formativos do componente curricular em Física.

\subsection{A ORGANIZAÇÃO DO COMPONENTE FÍSICA NO ENSINO MÉDIO}

Quanto à organização dos currículos de Física, propõe-se na BNCC a divisão em seis Unidades Curriculares de 01 a 06, que contemplam os campos de conhecimento da Física respectivamente, Movimentos de Objetos e Sistemas, Energias e suas Transformações; Processos de Comunicação e Informação; Eletromagnetismo - Materiais e Equipamentos; Matéria e Radiações - Constituição e Interações; e Terra e Universo - Formação e Evolução.

Apesar da importância de todas as Unidades Curriculares do Componente Física, o escopo desse artigo limita-se a temática da Unidade Curricular 06 - Terra e Universo: Formação e Evolução, as demais servirão de sugestões a trabalhos futuros.

Nessa Unidade Curricular permeia-se desde a gravitação universal que coordena a dança dos corpos celestes, até as hipóteses sobre os primeiros momentos do surgimento das forças, estuda-se a visão contemporânea do Universo e nele galáxias e estrelas, comparando-se com a herança de cosmologias de outras épocas - ou seja, modelos Cosmológicos da antiguidade, o estudo do funcionamento e da evolução de estrelas, a compreensão da formação de nosso Sistema Solar e à investigação de condições para que surja a vida em outras partes do Universo.

Nota-se que há uma convergência histórica nesse aspecto, ou seja, a História da Ciência inserida nas observações científicas, o que de fato significa a reaproximação entre o ente histórico e o científico que por vezes não é observado nas aulas de um modo geral, ou pelo menos, não é mencionado de forma alguma.

\subsection{OBJETIVOS DE APRENDIZAGEM}

A tabela a seguir, apresenta os objetivos de aprendizagem da Unidade Curricular Terra e Universo da BNCC e sua relação conceitual com os eixos formativos. 
Tabela 1: Objetivos de Aprendizagem e eixos formativos

\begin{tabular}{l|c}
\hline \multicolumn{1}{c|}{ Objetivos de Aprendizagem } & Eixo \\
\hline $\begin{array}{l}\text { Explicar as interações astronômicas, em diferentes âmbitos, do Sistema Solar ao } \\
\text { intergaláctico, utilizando o conhecimento da atração gravitacional para identificar e } \\
\text { estimar distâncias, massas, energias e tempos envolvidos. }\end{array}$ & CC \\
\hline $\begin{array}{l}\text { Apresentar modelo simplificado da formação e constituição de estrelas, em função da } \\
\text { auto gravitação de nuvens de hidrogênio, das reações de fusão em seu interior e da pressão } \\
\text { de radiação resultante que se contrapõe à pressão gravitacional. }\end{array}$ & CC \\
\hline $\begin{array}{l}\text { Identificar etapas da evolução de estrelas de diferentes dimensões, estimadas em função } \\
\text { de suas cores, brilhos e outras características observáveis e de modelos que interpretam } \\
\text { seus comportamentos. }\end{array}$ & $\mathrm{CC}, \mathrm{CSCH}$ \\
\hline $\begin{array}{l}\text { Compreender a origem dos elementos químicos, desde a nucleossíntese primitiva de } \\
\text { hidrogênio, hélio e lítio à nucleossíntese que se processa até o Ferro no interior das } \\
\text { estrelas e a de elementos mais pesados em supernovas. }\end{array}$ & $\mathrm{CC}$ \\
\hline $\begin{array}{l}\text { Compreender aspectos básicos do modelo padrão do Big Bang para a formação do } \\
\text { Universo, localizando e descrevendo os principais eventos espaço-temporais que o } \\
\text { caracterizam e identificando algumas lacunas desse modelo. }\end{array}$ & $\mathrm{CC}$ \\
\hline $\begin{array}{l}\text { Identificar os eventos associados à exploração do cosmo, relacionando-os a contextos } \\
\text { históricos, políticos e socioculturais, como a corrida espacial, a Guerra Fria e a disputa } \\
\text { política e econômica entre nações. }\end{array}$ & $\mathrm{CSCH}$ \\
\hline $\begin{array}{l}\text { Consultar fontes, sistematizar informações e avaliar criticamente as hipóteses científicas } \\
\text { e condições para a existência de vida fora da Terra, também exploradas em obras de ficção } \\
\text { literária e cinematográfica. }\end{array}$ & $\mathrm{CC}, \mathrm{CSCH,} \mathrm{PPI}$ \\
\hline $\begin{array}{l}\text { Comparar modelos explicativos da origem e da constituição do Universo, segundo } \\
\text { diferentes épocas e culturas, tais como a cosmologia de povos primitivos, a do mundo } \\
\text { grego do geocentrismo ao heliocêntrico. }\end{array}$ & CSCH \\
\hline $\begin{array}{l}\text { Produzir textos utilizando unidades cosmológicas, como unidade astronômica, ano-luz e } \\
\text { parsec, comparando com as do cotidiano, para estimar distâncias e tempos de percurso da } \\
\text { luz de planetas e estrelas e galáxias, avaliando limites de viagens no espaço sideral. }\end{array}$ & LC \\
\hline
\end{tabular}

Observa-se na tabela acima que a maioria dos objetivos de aprendizagem da Unidade Curricular proposta, tem como eixo formativo o eixo do conhecimento conceitual (CC), o que sintetiza o objetivo desse campo de atuação - o campo conceitual apenas. Os objetivos de aprendizagem apresentam realmente um nível de competência bem satisfatório, permeando a possibilidade de uma análise mais profunda de cada tema, e não mais, como nos (PCN), que envolviam noções elementares e conceituação simples, nisso observa-se uma evolução significativa na proposta.

A exemplo, o objetivo de aprendizagem (linha 5 da tabela) de eixo formativo (CC): Compreender aspectos básicos do modelo padrão do Big Bang para formação do Universo, localizando e descrevendo os principais eventos espaço-temporais que o caracterizam e identificando algumas lacunas desse modelo. Observa-se que a abordagem agora se tornou mais complexa, isso na proposta ganha corpo, ou seja, a subdivisão de um tema em subtemas auxiliares do objetivo de aprendizagem proposto.

"Relação entre idade cósmica e temperatura do Universo; radiação cosmológica de fundo; eventos marcantes como a separação das 4 forças na evolução temporal, formação das galáxias, formação do sistema solar, surgimento da vida, evolução do Homo sapiens; lei de Hubble, paradoxo de Olbers; características que o Big Bang não explica, por exemplo, o tamanho das galáxias, a estrutura não homogênea do Universo, a densidade de energia do Universo; modelos alternativos, como o do estado estacionário".

A abordagem conceitual é bastante sólida, observa-se no exemplo que embora o Big Bang seja aceitável pela maioria da comunidade científica, esse tema é passível de limitações, indagações ou inferições, e o exemplo não omite isso.

Embora a parte teórica da Astronomia não seja tão simples assim, talvez, o desafio maior seja a inserção dessa proposta nas discussões em sala com os pares, na maioria das vezes nas escolas públicas principalmente, alguns dos livros didáticos não contemplam assuntos tão complexos para discussão. Ressalta-se ainda, que a formação ou capacitação do professor também contemplada pela proposta da BNCC deve ser de fato voltada ao perfil de análise e investigação científica, do contrário, a proposta não terá o resultado esperado como as propostas anteriores. A formação docente é primordial, a estruturação dos espaços pedagógicos tais como laboratório, biblioteca, uma necessidade emergente e a restruturação e reformulação dos livros didáticos essencial. 
Dentre todos os objetivos de aprendizagem propostos na tabela 1, o último merece especial atenção pelo fato de que engloba a realfabetização científica. Na escola observa-se que a produção textual da maioria dos alunos é deficitária ou não inteligível, a maioria possui um grave problema de interpretação e produção textual, mais a proposta é válida e desafiadora.

\section{RESULTADOS E DISCUSSÃO}

Alguns comentários e discussões já foram realizados anteriormente durante a fundamentação, entretanto, urge a necessidade de uma análise mais criteriosa e sistemática dessa proposta. Como observado, a proposta alinha-se as bases curriculares de países desenvolvidos, como Estados Unidos e Austrália.

Em ambas, a necessidade da retomada da História da Ciência e a inserção ao currículo é notória. Por exemplo, no documento Science Education for the future ficam bem claras as razões da inserção de um currículo que atenda a história e a natureza da ciência, afirma ainda que o currículo deve proporcionar aos jovens uma compreensão de algumas ideias-chave sobre a ciência, isto é, as ideais sobre as maneiras pelas quais o conhecimento confiável do mundo natural tem sido e está sendo obtido, elenca Beyond (2000).

Na Austrália, o desenvolvimento do currículo Australian Curriculum, Assessment and Reporting Authority é fundamentado pela declaração de Melbourne sobre metas educativas para jovens australianos e foi adaptada pelo Conselho Ministerial daquele país em 2008 e estabelece que o currículo de ciências gire em torno de três áreas interligadas: a compreensão da ciência; habilidades de investigação científica e a ciência como um esforço humano.

Na realidade há uma conexão mesmo que discreta entre as propostas curriculares Americana e Australiana com os eixos formativos propostos na BNCC brasileira, por mais que os desafios aqui sejam bem maiores, pelo fato de que não dependem apenas do professor somente, ou do aluno, ou da escola apenas, mas de todo o sistema educacional brasileiro, que embora esteja ressurgimento e inovando com alternativas, amarga ainda os piores resultados educacionais do mundo.

A implementação da BNCC contribuirá com a formação de professores, produção de material didático e avaliação, a referência é comum, evidentemente, a BNCC não é de forma alguma a solução de todos os problemas educacionais do Brasil, mas será ancora para o início de políticas públicas voltadas a necessidade do sistema educacional.

Por mais que a BNCC contemple os conceitos elementares sobre a Terra e o Universo, há necessidade em si ampliar o debate acerca da reformulação dos livros didáticos. A maioria dos livros didáticos de Física atuais não traz de forma coerente a respeito da Astronomia - surgimento, desafios, fatos históricos, aliás, especialistas mostram que alguns não trazem nenhuma informação a respeito da Astronomia como ciência.

Dentre os erros ou equívocos apontados pelos especialistas, destacam-se erros sobre as estações do ano, fases da Lua, movimentos da Terra, estrelas, números de satélites, características planetárias, aspectos gerais de ordem histórica relacionados com Astronomia.

Por exemplo, a maioria dos livros segundo Bizzo et al (1996), afirmam que o planeta realiza dois tipos de movimento, o de rotação e o de translação, para os autores, esse conceito está incompleto, porque na verdade a Terra possui um movimento apenas que se decompõem em diversos outros até o momento catorze movimentos.

A ideia que as grandes descobertas científicas são produtos de acidentes ou casualidades são muitas, estas suposições ou inverdades, são denominadas de mitos científicos e reprodução erroneamente de uma pseudo-história, que muitas vezes são absorvidas pelos alunos como verdade, normalmente, a pseudo-história apoia-se em concepções de senso comum sobre ciência e como ela funciona, Logo, torna-se desprovida de qualquer fundamentação científica, caracterizando-se pelas histórias falsas da ciência - pseudociência, isto é, fatos que se contam e que não aconteceram como, por exemplo, cita Martins, a maça caindo na cabeça de Newton, Galileu jogando bolas do alto da torre inclinada de Pisa, Arquimedes correndo nu pelas ruas de Atenas gritando - Eureca! e muitas outras. Obviamente, é claro, que uma vez conhecedor de tais erros, para Allchin (2004), cabe ao professor esclarecer os estudantes em vez de continuar proclamando o erro. 
Contudo, não se pode descartar, o fato de que alunos e professores possam também colaborar com a divulgação desses erros científicos, concepções mal interpretadas ou conteúdos mal compreendidos, podem também comprometer a veracidade das informações. A quantidade de conteúdo também sobre Astronomia nos próprios livros é insignificante diante de outros conteúdos do livro, segundo Trevisan et al (1997), - ou seja, o professor fica desprovido de material para conceituação.

Outro ponto em desfavor, é que na rede pública de ensino, não há professores graduados em Astronomia ou Astrofísica, a maioria dos professores são leigos na formação acadêmica, ou seja, a maioria dos professores que ensinam tais conceitos são professores de Matemática, Física ou Química. A proposta da BNCC contempla a formação do professor para esse fim, apesar de que não há disponibilidade carga horária efetiva para aulas de Astronomia, por exemplo, e cursos de graduação em Astronomia no país são escassos.

Nesse aspecto, uma saída seria as formações continuadas ou cursos de extensão nessa área para profissionais de áreas afins.

\section{CONCLUSÃO}

A iniciativa do Ministério da Educação (MEC) de uma proposta ousada e inédita como a BNCC é louvável, entretanto, alguns pontos da proposta necessitarão de discussões mais profícuas em relação a temas que fogem ao escopo ou ao poder de atuação da BNCC.

Um ponto crucial com relação ao sucesso ou insucesso da proposta nas escolas, no caso específico da reflexão sobre o ensino de Astronomia na escola pública é fato de que uma boa parte dos professores possui formação deficiente em Astronomia, em função da oferta de poucos cursos de graduação e de capacitação na área, aliás, isso fomenta as concepções alternativas do profissional o que em última instância compromete o aprendizado.

Ressalta-se ainda que em sua prática docente, o professor da rede pública em sua maioria, usa apenas como recurso de ensino, o livro didático. Como visto, a maioria dos livros apontam incoerências históricas e conceituais, o que aumenta a dificuldade de ensino de forma efetiva. Outra questão de impacto no aprendizado dos estudantes é a carga horária disponível na rede pública, insuficiente ou insatisfatória, geralmente, a carga horária disponível para o ensino médio diurno é de três aulas de Física semanais, no noturno apenas duas aulas semanais, obviamente, a proposta da BNCC é estender a discussão no âmbito das políticas públicas educacionais a respeito. Atualmente, alunos da rede pública brasileira ficam em média quatro horas por dia na escola, entretanto, em países como Japão, Finlândia e outros, onde o tempo de permanência na escola é maior do que a média brasileira, apontam resultados muito significativos na qualidade do ensino apresentados pelo Pisa ${ }^{1}$.

Nesse aspecto, outro problema incorre na escola pública brasileira: a falta de estrutura em todos os aspectos - a maioria não possui espaços pedagógicos adequados para a produção científica ou para atividades que vislumbrem nos atores o protagonismo científico - isso é notório. Há poucas escolas no país em regime de tempo integral, talvez a ampliação do quadro de instituições de tempo integral fosse uma das possíveis soluções para essa demanda, entretanto, ampliando-se o período de permanência, amplia-se também o efetivo docente, corpo técnico, pessoal de apoio e outros consequentemente seriam outros entraves.

Além de todos os fatores e fragilidades apresentados, outros são evidenciados tais como a escassez de material bibliográfico; falta de formação adequada, os professores mantêm as concepções sobre os assuntos relacionados e muitas vezes incorrem em erros conceituais, a ausência de adesão de gestores e professores em atividades que promovam a difusão da disciplina ou eventos, no caso, da Astronomia - Olímpiadas de Astronomia, Concurso de Lançamento de Foguete e outros do gênero.

Ressalte-se que a restruturação curricular nacional deve está preparada para todas as demandas advindas da implementação da proposta nas escolas em tempo integral, do quadro completo de

\footnotetext{
${ }^{1}$ Programme for International Student Assessment - Programa Internacional de Avaliação dos Estudantes é uma iniciativa de avaliação comparada, aplicada a estudantes na faixa dos 15 anos, idade em que se pressupõe o término da escolaridade básica obrigatória na maioria dos países.
} 
professores, da formação ou capacitação docente, a restruturação dos espaços laboratoriais e de pesquisas, ou do contrário, não basta, reestruturar o currículo em si, a própria estrutura do sistema necessita de uma reestruturação, essas discussões principalmente, em um momento inédito de discussão da Base Nacional Curricular Comum são imprescindíveis ao futuro do ensino de Ciências no país, especialmente, no ensino de Física e subáreas.

\section{AGRADECIMENTOS}

Aos professores das disciplinas do mestrado profissional em ensino de Física da Universidade Federal do Sul e Sudeste do Pará pelo apoio sem precedentes.

\section{REFERÊNCIAS BIBLIOGRÁFICAS}

1. Allchin D. Pseudo history and Pseudo science. Science \& Education 13, 179-195, 2004.

2. Arroyo, M. G. Currículo, território em disputa. Petrópolis: Vozes, 2011.

3. Bizzo N. Ciências: fácil ou difícil? São Paulo: Ática, 1998.

4. Bizzo N. et. al. Graves erros de conceito em livros didáticos de ciência. Ciência Hoje, v.121 n.21,p.26-35, Jun. 1996.

5. Beyond 2000: Science education for the future. The report of a seminar series funded by the Nuffield Foundation. Acesso em 09 de Jul. 2016.

6. Brasil. Ministério da Educação. Secretaria de Educação Média e Tecnológica. Parâmetros Curriculares Nacionais: Ensino Médio. Brasília: MEC, 2000.

7. Brasil. Ministério da Educação. Secretaria de Educação Básica. Base Nacional Comum Curricular: Educação Básica $2^{\mathrm{a}}$ versão revista. Brasília: MEC, 2016

8. Guerra A, Quintal JR. A História da Ciência no processo de ensino-aprendizagem. Física na Escola, v.10, n.1, 2009.

9. Trevisan RH. et al. Assessoria na avaliação do conteúdo de Astronomia dos livros de ciências do primeiro grau. Caderno Catarinense de Ensino de Física, v.14, n. 1, p. 7-16, 1997. 